\title{
Editorial
}

\section{Changing choices in health care: implications for equity, efficiency and cost ${ }^{1}$}

\author{
GWYN BEVAN* \\ Professor of Management Sciences, Department of Management, London School of Economics and Political Science, \\ London, UK \\ JAN-KEES HELDERMAN \\ Assistant professor, Department of Public Administration \& Political Science, Radboud University, Nijmegen, \\ The Netherlands \\ DAVID WILSFORD \\ Professor of Political Science, Department of Public and International Affairs, George Mason University, Fairfax \\ Virginia, USA
}

\begin{abstract}
Although choice may be seen as an end in itself, the papers included in this special issue of Health Economics, Policy and Law, examine choice policies in European systems of health care, which aim to be effective instruments for ameliorating the systemic pressures from the iron triangle of equity, efficiency, and cost. Three papers consider the nature of differences between and within countries following the Beveridge and Bismarck models of financing and organising the delivery of care, and how choices are changing within different systems. Within countries following the Beveridge model, current policies in England, Denmark and Sweden emphasise increasing patient choice of provider. Within countries following the Bismarck model, current policies in France and Germany seek to restrict choice of specialists by introducing 'soft' gatekeeping; and in the Netherlands there is a system of managed competition with choice of insurer that, in principle, allows insurers to contract selectively
\end{abstract}

1 Three of the papers included in this Special Issue of Health, Economics, Policy and Law, on choice in European systems of health care, were presented at a series meetings of the European Health Policy Group (EHPG) between 2006 and 2008 at the Instituto Superior de Economia e Gestao in Lisbon, the Bertelsmann Foundation in Berlin, the Economic and Social Research Institute in Dublin, and the London School of Economics and Political Science (LSE). Gwyn Bevan organised the selection and discussion of papers at these meetings. We are grateful to Carolyn Tuohy for giving an overview of these papers and the editorial, and commenting on each when these were discussed at a meeting focused on this special issue at the LSE in September 2008. In addition, we invited Mark Schlesinger to contribute a commentary and included a fourth paper presented at the EHPG meeting at LSE in September 2009 organised by Adam Oliver. The three editors agreed on papers to be selected for this special issue. David Wilsford prepared a first draft of this editorial to lay out the principal argument. Gwyn Bevan revised this to offer a commentary on the papers included in this special issue, and all three of us contributed to the redrafting.

*Correspondence to: Gwyn Bevan, Department of Management, London School of Economics and Political Science, Houghton Street, London WC2A 2AE, UK. Email: R.G.Bevan@lse.ac.uk 
with providers. A fourth paper considers how government policies that seek to restrict choice within systems of universal coverage have been subject to challenges in the courts. A commentary explores the implications of the fraught and complex nature of choices between insurers and providers of health care for designing effective choice policies.

\section{Introduction}

The triangle of equity, efficiency and cost has been the overarching bane of health economists and health policy analysts for decades. How does one best reconcile the tension between the corners of ensuring equity (access by need and not by ability to pay), with efficiency (generating incentives to reduce costs and improve quality) and control total costs (paying for it all without breaking the national bank - as defined by total expenditure as a percentage of GDP)? Equity, efficiency and cost frame the constant tension permeating the equilibrium of this health policy triangle in any one system at any given moment. As far as we know, no nation's government anywhere feels that they have struck the balance of an optimal and sustainable equilibrium. Indeed, Weale (1998) has argued that the cost constraint means that the three desiderata of a comprehensive service freely available to all of high quality generate an inconsistent triad: 'a collection of propositions, any two of which are compatible with each other but which, when viewed together in a threesome, form a contradiction'. Within the confines of the overarching triangle - a conceptual iron triangle if ever there was one - in the last decade, governments in various Organisation for Economic Cooperation and Development (OECD) countries have worked to change the nature of choice as a new variable in this calculus with the objective of ameliorating the tensions of the problematic equilibrium of each system.

The common shorthand used to categorise systems is between the Beveridge and Bismarck models. The archetypal Beveridge model is the traditional system of the United Kingom, of a single payer, financed by national taxation, with a National Health Service in which providers of publicly financed services are owned publicly, and access to hospital specialists is typically by referral via a general practitioner (GP). The archetypal Bismarck model is the traditional system of Germany, financed by multiple insurers, with employer-based schemes supplemented by the state, in which providers are privately owned and patients have direct access to specialists. We discuss below the important variations within these broad categories and these variations are further explored by Or et al. (2010). In this special issue, we consider three sets of government choice policies that reflect fundamental differences between the different systems, in terms of their capacity to control total expenditure on health care and the nature of choices to which people have become accustomed.

First, governments in countries with the Beveridge model (England, Denmark and Sweden), which have been relatively successful at controlling total expenditure 
on health care and have traditionally given limited choice to their patients, because they have relied on their GP as the gatekeeper, guide and coordinator of their health care (the extent to which GPs actually fulfil these roles varies). In this set of countries, the emphasis is on increasing choice of hospital for elective care (Bevan and van de Ven, 2010; Dixon et al., 2010; Or et al., 2010).

Second, governments in countries with systems closer to the Bismarck than Beveridge model (France or Germany), which have experienced problems in controlling total expenditure on health care and their populations traditionally have had no choice of insurer, but free choice of specialist or GP. In these countries, governments are seeking to reduce choice of specialists by types of 'soft' gatekeeping (Or et al., 2010).

Third, the Netherlands, which has a Bismarck model, but has been relatively successful at controlling total expenditure on health care, has introduced choice of insurer and with more information for patients on choice of provider (Bevan and van de Ven, 2010; Dixon et al., 2010).

This special issue also includes a paper that explores a complication for governments from legal challenges to policies that restrict publicly financed choice, judges' decisions on individual cases may have far-reaching systemic consequences (in the European Union (EU) and Canada; Flood and Haugan, 2010); and a commentary that explores the implications of the fraught and complex nature of choices between insurers and providers of health care for designing effective choice policies (Schlesinger, 2010).

Therefore, one of the tensions constantly at play in this issue is the use of increasing choice to improve access (e.g. by reducing waiting times) and through competition to improve quality, and reducing choice in order to reduce costs (guided or misguided as that may be).

\section{Definitions, or ... what are we really talking about?}

Let us start with definitions, to help ensure that we are all talking about the same thing in this special issue.

\section{Equity}

Conceptually, equity is the state of something being fair. It is also, therefore, closely associated with the ideals of justice and impartiality. However, equity is a proportional criterion; it refers to the equivalence of efforts or sacrifices on the one side and rewards on the other. In health care, the basic sense of equity has to do with the (un)fairness of treating people's health (or sickness) without prejudice. Secondary or tertiary attributes are those that are not directly tied to the state of the given person's health at that moment. The starting point is that a system that excludes many people from access to basic care (which may be hard to define, but this is ultimately the result of collective choice processes for which 
we reserve the term democratic choice) cannot be characterised as equitable. A further distinction in the case of health care can be made between horizontal equity in access, referring to an equal amount of supply for equal needs, and vertical equity in ability to pay, which is related to income. Equity of access denotes the ability or right to enter a system according to need and not according to the ability to pay, social class or where people live. Need can be defined in terms of being sick or capacity to benefit from health care (including palliative care), and these different definitions may mean different choices in giving priority to those who need care.

Access is a highly differentiated concept because healthcare systems are all complex and institutionally nuanced in their levels and categories of services, both vertically and horizontally. The well-established link between poverty and ill health means that even in systems of health care that strive for equity in access there is inequity in outcomes (as in England; Bevan, 2009). The policy objective of equity provides the rationale of government's central involvement in health care. Even if most of the healthcare systems do not satisfy the economic criterion of being a public good, many societies choose to treat it as one. Access also creates problems, insofar as the most of the costs of health care typically are paid not at the point of consumption, but are essentially financed by transfer payments from those who can pay (the young, healthy and rich) to those who are in need (the old, sick and poor; Evans, 1987).

\section{Cost}

The problems of financing the costs of health care have complex ramifications on every system and certainly on all of the systems included in this special issue. Governments worry about escalating expenditure of health care, but not, for example, on computers, because the latter is the outcome of myriad decisions in competitive markets where the cost of a computer is paid when it is bought. As Arrow (1963) highlighted, health care differs from other commodities because it is uncertain, costly and there is information asymmetry. Moreover, it is because modern governments are implicated to such an all-encompassing degree in paying for health care that the question of what it costs is inevitably politicised.

Some also argue that the way in which health care is financed creates the wellknown problem of 'moral hazard' in insurance, to which the conventional insurance solution is the user charges of some kind. The efficacy of user charges for health care is contested; however, information asymmetry means that doctors, rather than patients, make decisions on demand and supply (Evans, 1987). User charges bring administrative costs and create the problem of reconciling two conflicting objectives: setting charges high enough to cover the administrative costs and deter patients from 'unnecessary' demands, but not so high that charges become a barrier to timely access to 'necessary' needs (where doctors are 
better placed to distinguish between the 'unnecessary' and the 'necessary'). The famous RAND health insurance experiment, which, it is argued, still speaks to the current healthcare debate although it was completed in 1982 (Brook et al., 2006), produced strong evidence of the disadvantages of cost sharing; in that study, visits were reduced indiscriminately (whether care is needed or not), while having little effect on costs once care was sought.

Making services free (or heavily subsidised) at the point of access means that we lack the feedback of normal markets that tell providers of services where the value of what they supply does and does not exceed what consumers are willing to pay. Hence, there is no such information for health care, and where demand exceeds supply, other kinds of rationing than by price emerge, such as long waiting times, which may result in inequity. Even within publicly financed systems, the articulate well-educated middle classes tend to be more skilful users of 'free' systems and are able to use 'sharp elbows' to achieve better access (Le Grand, 2007). Where they have access to private services, this offers them an escape from suffering long waiting times. Therefore, many suggest that there is intrinsic conflict in publicly financed health care, which aims to be comprehensive, between equity and high quality (Weale, 1998). It is not possible to finance publicly an affordable comprehensive service available for all that meets the demands of the rich for a high-quality service. If the quality of public health care is perceived to be unsatisfactory, then whatever policies governments adopt, they confront serious problems. If government policy is permissive to the development of privately financed health care, this will be used by the rich, who will increasingly resist paying for a public service that they do not use. This will have a further deleterious impact: as Richard Titmuss observed, 'Another element is the historical evidence we have that separate discriminatory services for poor people have always tended to be poor quality services' (Alcock et al., 2001: 121). ${ }^{2}$ This can create a vicious circle. If governments seek to escape from it by a policy that legislates against the development of privately financed health care, failures of public services can result in this legislation being challenged (Flood and Haugan, 2010).

Hence, financing the costs of an equitable system raises a series of contested issues about the public/private mix of health care: Ought public funding entail a defined basic minimal package of services? Ought individuals be allowed to buy privately more services or at higher quality (including more rapid access) or both? Ought individuals be allowed at the same time to receive publicly funded medical and nursing care and pay privately for high-cost drugs (e.g. for cancers), which are not publicly funded (Richards, 2008)?

2 This is often taken to mean 'Show me a service that only the poor use and I will show you a poor service'. The actual observation cited in this paper was originally made by Richard Titmuss in a lecture he delivered to the British National Conference on Social Welfare in 1967. We are grateful to Howard Glennerster for giving us the origins of this citation. 
During the fiscal crises of the late 1970s and early 1980s, the model in which government acted as insurer in a single-payer system offered the attraction of a capacity to contain the total costs of health care. This was demonstrated in a series of papers by Evans and others that examined the natural experiment offered by the introduction of universal coverage in Canada (Evans, 1987; Evans et al., 1989; Evans et al., 1991). Before 1971, there were strong similarities in the arrangements for the financing and delivery of health care in Canada and the United States. After 1971, all the Canadian provinces had universal coverage through a single-payer system and hospital services became free at the point of delivery; but the United States continued with incomplete coverage and high user charges. These two systems had similar total expenditure on health care as a percentage of GDP in the 1960s and up to 1971, when Canada spent $7.2 \%$ and the United States $7.3 \%$ of GDP on health care (OECD, 2008). After 1971, there was continued escalation of total expenditure in the United States and relative cost control in Canada. The most recent data, for 2007, give total spend on health care as a percentage of GDP to have been $10.1 \%$ in Canada and $16.0 \%$ in the United States (OECD, 2008). For the countries included in this issue, the percentages were (from highest to lowest): France $11.0 \%$, Germany $10.4 \%$, Denmark $9.8 \%$, the Netherlands $9.8 \%$, Sweden 9.1\% and the United Kingdom 8.4\%.

It is believed and commonly found that Beveridge single-payer systems perform better on cost control than Bismarck multiple payer systems (Or et al., 2010), and this is illustrated by differences between the United Kingdom and Germany. The United Kingdom has been an exemplar of tight cost control (exceptionally, the fiscal crises of the UK National Health Services (NHS) have been those not of cost escalation, but of 'underfunding', see Bevan and Robinson, 2005). Germany has consistently spent a relatively high percentage of its GDP on health care and had problems in bringing this expenditure under control. Health care in Denmark and Sweden is based on the Beveridge model, but traditionally managed and financed by local government, not by central government, whereas in the Netherlands, it is based on the Bismarck model. The Netherlands, however, spends a similar percentage of its GDP on health care to that of Denmark and Sweden. Hence, differences within the broad categories of the families of Bismarck and Beveridge models may be as important as the differences between these categories. Tuohy (2008) has also highlighted that of the top six countries in terms of public expenditure as a percentage of GDP in 2005 (excluding Iceland), three are Bismarckian (France, Germany and Austria) and three are Beveridgian, but highly decentralised in both raising revenue and in expenditure (Norway, Denmark and Sweden). This led her to pose the question: does this mean willingness to pay publicly for health care is greater where funds are raised and spent by a body predominantly identified with health care? So is the key to cost control that this is exercised by central government? In the Netherlands, unlike in France and Germany, macro healthcare spending is contained by cost control through a combination of corporatist and etatist 
governance arrangements (Helderman et al., 2005). Hence, will the introduction of 'soft gatekeeping' in France and Germany improve cost control without involving the government in determining macro healthcare spending?

\section{Efficiency}

There are two desirable types of efficiency that ought to be sought by systems of health care: technical (for a given service achieving the same quality at reduced costs or higher quality at lower cost) and allocative (organising the optimal mix of services). Perfect markets achieve both: consumers allocate their spending to maximise their utility, and they choose between competing providers. This consumer choice drives providers to continue to seek technical efficiency (or be forced to exit the market). But, separation between finance and consumption in systems of health care creates problems over how expenditure ought to be allocated between different types of services. An absence of choice and competition removes pressure on providers to seek technical efficiency. The predictable outcomes of such systems are that supply reflects past allocations of resources, that there are shortages in supply (illustrated by long queues), and that, for similar types of care, there are endemic variations (in supply, quality and costs). Governments discover, however, that when they try to introduce competition, they often experience problems in allowing one of the key drivers of efficient markets to occur: for failing insurers or hospitals simply to exit the market.

Governments that have succeeded in securing a degree of control over the costs of health care have faced problems over quality. In health care, quality refers to both the degree of excellence of the service provided and the speed of access. As such, it is perforce a concept rooted in relativity; excellence as compared to what? Quality is a highly differentiated concept in healthcare systems, because health care is complex and customised. Within, say, the production of cars, certain manufacturers achieve an enviable reputation for high quality of all their products. It is much harder to ensure high quality across services provided by autonomous professionals delivering primary or acute hospital care; indeed, it is common to have services of varying quality within the same primary care organisation or hospital. Therefore, 'higher' quality may characterize one level or category of care, whereas 'lower' quality may characterize another level or category of the very same system.

By the late 1980s, the United Kingdom and the Netherlands were looking for ways to improve the efficiency of their systems of health care. Each sought to introduce competition, based on the ideas of Alain Enthoven (1978, 1980 and 1985), between providers in an internal market in the United Kingdom (Bevan and Robinson, 2005) and between sickness funds in the Netherlands (Helderman et al., 2005). The idea of an internal market was widely copied in other countries. Competition failed to materialise substantively in the internal market in the United Kingdom (Ham, 1996), and paradoxically successive 
ministers of Conservative governments claimed, in retrospect, that they had not sought to introduce competition into the NHS (Ham, 2000). The Labour government, following the 1997 election, nevertheless, made great rhetorical play of abandoning 'competition' in the search of a 'third way' (Bevan and Robinson, 2005). The government maintained the purchaser-provider split and later reintroduced the idea of competition with patient choice. Following a devolution to the countries of the United Kingdom, England has become the odd man out (Greer, 2008); Scotland (Woods, 2001) and Wales (Welsh Assembly Government, 2008) have abandoned the idea of competition and the purchaser-provider split. Introducing competition between sickness funds in the Netherlands, with the objective of maintaining the principle of solidarity, required the design of a system of regulation to counter 'cream skimming'. As a consequence, progress in the Netherlands was initially very slow; but, there has been consistent development and implementation of that policy (Helderman et al., 2005; Bevan and van de Ven, 2010). Belgium, Germany, Israel and Switzerland are also developing systems of insurer competition (van de Ven et al., 2007).

\section{Choice}

Insofar as choice is an attribute of any system, it implies a selection of alternatives. We have no choice if we cannot pick. We may choose A over B, or B over A, to accomplish a given objective. The choice between these alternatives implies both a meaningful difference and a meaningful similarity. Similarly, both choices are reasonable alternatives offered to achieve the goal. Choosing A over $\mathrm{B}$, or vice versa, makes a difference in some aspect of the path towards the objective or in the final character of the objective obtained.

Of all the nuanced concepts at play presented in this special issue, choice is perhaps the most complex of all in its interlocking, overlapping, exclusionary and cascading effects on other variables of the system (Schlesinger, 2010). In democratic, capitalist and welfare states, citizens have substantial political and economic freedoms. Next to the mechanism of 'voice', the possibility to choose and to fulfil our own preferences is essential for the legitimacy of these systems, with choice being an end in itself (the evaluative reason). But, choice is also seen by some as one of the most effective instruments for enhancing the responsiveness of governments and markets to the needs and demands of their citizens and consumers (the effectiveness reason; Le Grand, 2007). As Schlesinger (2010) points out, 'choice' may enhance the power of 'voice'. It is only by means of a subtle combination of the mechanisms of 'voice' and 'exit' in all sorts of social spheres and institutional arrangements that we can arrive at a high degree of loyalty and solidarity. As argued above, there are problems if the rich pay taxes for, but do not use, publicly financed services.

The issue of choice raises a number of troubling questions (Schlesinger, 2010). Does the very availability of choice make those that choose better off, no matter 
what their choice among the available alternatives is? Does choice mainly accomplish the goals of those who decide which alternatives to make available, by subtly structuring outcomes through seemingly unfettered choice, which is in fact considerably fettered after all? What are the collective consequences of individual choices? Can structuring alternatives from which to choose serve to lower costs systemically through competition? Or does providing alternatives increase costs by requiring increases in the availability of supply, or removing or restricting the ability of third parties to control costs? Is choice a good in itself? Does it do good? Ought it be controlled?

The arguments over policies to increase choice are not over the evaluative reason, but over the effectiveness reason. Will these policies result in health care, through careful design, mimicking the desirable characteristics of normal markets (of improvements over time in responsiveness, or improving quality or reducing costs or a combination of these), without the undesirable characteristics of the consequences of relying on the price mechanism? For these beneficial outcomes, choice needs to be available and to be exercised. The United States is perhaps the country with most consumer-oriented arrangements for health care, and, for those with insurance coverage, there is choice of both health plan and provider, although choice of the former has implications for the choice of the latter (Schlesinger, 2010). A systematic review of the US literature has found mixed evidence of the impacts of public reporting on both kinds of choices (Fung et al., 2008). This evidence raises questions about the effectiveness of increasing choice in countries where this is a novelty. There are also questions over how far 'consumers' of health care ought to be empowered to exercise choice; should this be limited, as in England, to publicly financed providers on grounds of quality for the same types of care at the same price (i.e technical efficiency)? Bevan and van de Ven (2010) explore the implications of introducing choice and competition between purchasers in the English NHS based on the Dutch reforms. One question is whether to allow choice to extend, as in the Netherlands, to the option of buying supplementary health insurance (on top of the mandatory basic health insurance package) so that those able to spend more can top up the public element to buy additional services or more choice. Such policies are likely to raise problems of creating inequities of access depending on ability to pay. We have three different kinds of choice policy experiments taking place.

First, in the Beveridge systems policies in England followed those in Denmark and Sweden to emphasise choice as a means of introducing incentives for improving quality and reducing waiting times (Secretary of State for Health, 2002; Or et al., 2010). Within England (Bevan and van de Ven, 2010; Dixon et al., 2010), the emphasis is on patient's choice between public and private providers in a quasi market; those who want to pay more have to opt out of the NHS and pay the full costs of private care. Patient's choice is seen as key to delivering responsive, patient-centred services by offering powerful incentives 
for providers to improve the quality of their services. There are four principal elements to these reforms: a national electronic booking system ('Choose and Book'); increasing the range of providers available (through Independent Sector Treatment Centres); a website providing information on available services and comments posted by users (NHS choices); and a payment system based on Diagnosis-Related Groups (DRGs) ('Payment by Results') in which hospitals are paid the same rate for the same type of case, with the idea that providers will compete on the basis of quality. A recent authoritative report (Audit Commission and Healthcare Commission, 2008; Bevan, 2008) found that there was strong evidence that 'patients wanted a high quality, local hospital that they could access' (where 'local' would typically mean the nearest acute hospital), but not that the choice policy had caused hospitals to improve and hence bring this about. The report identified both difficulties in implementing choice and a lack of detailed information about it (Dixon et al., 2010), and found 'no evidence that the choice policy was resulting in significant changes for the patient or to patient's pathways', suggesting that it was not driving improvements in quality by provider competition.

Second, within the Bismarck system of the Netherlands, the emphasis is on a system that reimburses choices made by individuals between insurers that compete in offering different packages in terms of payments (including copayments) and coverage. Insurers in turn are empowered to contract selectively with providers. The competitive trick in the Dutch health insurance system is that, if health insurers are able to manage health care more efficiently than their competitors, then they can make more profit, or charge a lower premium and thus attract more enrollees. There are mandatory open enrolment periods on an annual basis, during which enrollees are free to choose another health insurer at its prevailing community-rated premium with insurers' incomes adjusted by a risk equalisation scheme (to counter 'cream skimming'; Helderman et al., 2005). Although health insurers have been given the freedom to contract with selected providers and to negotiate contractual arrangements, selective contracting has remained a marginal phenomenon; this instrument has been restricted to maternity care, physiotherapy and ambulatory psychological care. One reason for this is that insurers are afraid of losing customers when they actually restrict their choice of provider (Bevan and van de Ven, 2010; van de Ven et al., 2009: 110).

Third, within the Bismarck systems of France and Germany, there has been the introduction of a policy of 'soft gatekeeping' as a means to restrict choice (Or et al., 2010), which may alter the ways in which patients select their primary care physician (Schlesinger, 2010).

It would be worth knowing more about how the traditional arrangements of choice for patients evolved in different countries, how these features of totemic significance were influenced by the developments of the medical profession, and hence their influence on the 'accidental logics' of the different systems. Carolyn Tuohy (Tuohy, 1999) has argued that a country's system of health care reflects 
the 'accidental logics' of the political history of its creation; and this 'logic' then constrains subsequent developments so that these become path dependent. One crucial influence on choice has been the development of the medical professions. The different systems of the United Kingdom (Stevens, 2003) and the United States (Starr, 1982) can be seen to have been shaped by the different arrangements made for paying GPs and decisions on whether they were or were not allowed to care for their patients when they were admitted to 'voluntary' (i.e. not state financed) hospitals (Stevens, 2003: 32). In the United Kingdom, the referral system was established by the end of the 19th century so that 'The physician and surgeon retained the hospital, but the general practitioner retained the patient' (Stevens, 2003: 33, emphasis in the original). The outcome was the great and abiding division in British medicine between specialists and GPs (Honigsbaum, 1979). In the United States, in the early 20th century, financing the development of 'voluntary' hospitals' required patients who could afford to pay for this care, who were looked after by GPs. Therefore, GPs were allowed to admit patients to hospital, and the outcome was that the dominant model of US medicine is of specialists working from their own offices with admitting rights to hospitals (Starr, 1982: 162-169).

In the Bismarck countries, the nature of choice that patients had depended to a large extent on the historical structure of the sickness funds (whether they were regionalised or not) and the position that medical doctors (GPs and specialists) had in the administration of the sickness funds and the non-profit hospitals. Moreover, in a country like France, for example, as physicians in the 1930s were highly organised, they were able to insist on a fee-for-service payment system for ambulatory care, as a condition for their cooperation in a modest early effort to collectivise health care. This made it quite difficult even much later in the 20th century for the French state to envision attempting to change it (Wilsford, 1989). Indeed, the whole matter of path dependence of healthcare policy is deeply anchored in all the countries that we study here, not that it is inevitable. Under certain careful conditions, substantial change can occur, as we have seen over 20 years in the Netherlands (Bevan and van de Ven, 2010). But, substantial changes onto new policy trajectories are nonetheless rare, compared with the dragging weight of the past on the efforts of any new reform (cf. Wilsford, 1995). How easy is it for people in societies brought up within the tradition of a NHS model to develop, implement and make use of choice of provider? There is weak evidence that so far this matters to patients in England: what they want is a good local hospital. In France and Germany, are people troubled by the policy of 'soft gatekeeping' (Or et al., 2010)? In the Netherlands, do people value choice between insurers and choice between tailormade insurance packages? In the first year (2006), $18 \%$ of the Dutch population did choose another insurer (although nearly half of these were part of collective contracts between their employer and health insurers). In 2007, only 4\% changed their insurer. Have these various policies secured such commitment to 
increased choice or acceptance of restricted choice to the extent that these countries are moving onto new policy paths?

As Simon (1997) pointed out many years ago, the psychology of administrative decisions means that individuals lack complete knowledge of the available options and have to rely on their imagination to anticipate what they are likely to experience from the few options of which they are aware. He described such actual behaviour as 'satisficing' with bounded rationality rather than trying to optimise with a completely specified decision tree. Thaler and Sunstein (2008) have recently contrasted the behavioural model of decision-making of econs (economic man), as assumed in conventional micro-economics, with that of humans, from empirical evidence of actual decisions from the literature on carefully designed psychological experiments. Schlesinger (2010) points out that, for complex problems under conditions of bounded rationality, individual decision-making is liable to potential biases that need to be identified and taken into account. Choices in health care 'are immensely complex and fraught with emotional connotations, precisely the circumstances under which these decision pathologies are most likely to emerge' (Schlesinger, 2010).

Policies to increase consumer choice, as described in this special issue and in the academic literature, have focused principally on providing standardized information on the comparative performance of clinicians and insurers; engaging primary care physicians to assist their patients in their choice of specialists and hospitals, or both. However, Schlesinger points out that under conditions of bounded rationality, a third option would be of greatest value, namely funding third parties (e.g. patient navigators, information help lines) to help patients find relevant information and negotiate their way through the healthcare system. This was exceptionally a characteristic of the successful London Patient Choice Project, which was facilitated by Patient Care Advisors. They contacted patients who had been waiting a long time by phone or letter to offer them the option of going to an alternative hospital where they would be treated more quickly, answered their questions, and if the patient agreed to accept the offer of an alternative, made the necessary arrangements, offered continued telephone contact with the patient and provided support if any problems occurred and informed the patient's GP. Two-thirds of those who were offered the opportunity to go to an alternative hospital for shorter waiting times chose to do so (Coulter et al., 2005). The choice policy as subsequently implemented in England, however, lacks such a facilitator (Dixon et al., 2010).

Furthermore, for econs, if some choice is good, then more must be better; for bumans, bounded rationality means that 'although some choice is undoubtedly better than none, more is not always better than less' (Schwartz, 2004). The choice policy in England was developed from offering patients a choice between four and five secondary providers to virtually any provider. As Schlesinger argues, this expansion of the choice set can undermine the cognitive capacity for making coherent decisions. 
This special issue explores dilemmas and the problematic decision environments that surround and envelop changing policies for choices in health care, the contradictory character of instruments and goals, and the on-going shifting tensions inherent in these policies being played out within the triangle of equity, efficiency and cost, which characterize this era's macro-policy health universes in the developed countries. The following four papers give empirical evidence on the current state of choice policies in seven countries: Canada, Denmark, England, France, Germany, Sweden and the Netherlands. We have aimed in this editorial to explore conceptual difficulties from the various choice policies. The final paper, a commentary by Schlesinger, draws on research into the complexities of framing choices for health care to reflect on the different countries' policies.

Despite the attraction of choice and competition for contemporary health care reformers, there is considerable scepticism about the instrumental and institutional feasibility of the choice-enhancing mechanism of the market as a governance arrangement in health care. From the 1960s until at least the mid-1980s, Kenneth Arrow's seminal paper about uncertainty and information asymmetry in the medical care market served as a defining paradigm of the developing subdiscipline of health economics, with the policy implication that any medical market would be inequitable and inefficient (Arrow, 1963). Robert Evans (Evans, 1981) and Alain Enthoven (Enthoven, 1981) each identified varieties of integration between insurance and the provision of health care as a way of tackling the problems that Arrow identified. These alternatives included the idea of the Health Maintenance Organisation, where the seller of insurance integrates forward into health care; or where government takes over the insurance function. In the latter case, the role of government, as in Canada, may be limited to insurance, or as in the Beveridge systems in Europe, include also taking over the responsibility for running services.

Donald Light has argued that the current appeal to competition in health care is mainly politically and ideologically informed, not supported by any scientific evidence, and therefore potentially devastating in its consequences: 'The myth of efficiency, productivity, and accountability trumps the myth of trustworthy expertise applied altruistically to the needs of patient ... client, I mean customers. It is the master myth of society' (Light, 2000: 971). As Robert Evans (2005: 286) graphically described, trying to sustain solidarity in a marketlike environment requires such a strong and sophisticated regulation that it resembles trying to ride North on a South-bound horse. The creation of choiceenhancing institutional arrangements within systems that can contain costs and promote equity continues to be a major challenge. Perhaps the reason why policies of increasing choice continue to be popular in the absence of compelling evidence of benefits is that the alternative option of more supply-side regulation is seen to be even more unattractive.

Juran (1988) pointed out that 'every system is perfectly designed to achieve exactly the results it gets'. Each government naturally wants to remedy its 
systemic weaknesses in health care as compared with other countries. Problems arise when what is desired entails fundamental changes to the accidental logics of systems as they have developed in different countries. The English system is designed to achieve equity of access and macro-cost containment in a vertical hierarchical state, which creates tensions with trying to introduce choice horizontally in a more competitive (market-like) system arrangement. In France and Germany, there appears to be an assumption that gatekeeping is one reason for England's comparative ease in containing costs, but that is only one element of the English system. In France and Germany, because choice is seen as a right, the only feasible systemic change appears to be 'soft gatekeeping', that is, people can choose (at a price) whether they want to use, or avoid using, a 'gatekeeper'. More generally, governments that are expected to guarantee universal access, whatever the arrangements, can only allow healthcare markets to develop in insurance and delivery subject to strong regulation vis-a-vis exit; hence these markets will always lack the dynamism of normal markets where those that fail exit the market.

Where objectives conflict, they may need to be ranked hierarchically. The commitment that health care ought to be available according to need suggests that choice ought to be subordinated to equity of access. If some citizens (as is likely) have more choice than others, this threatens the principle of solidarity. Many years ago Wildavsky observed 'the rich don't like waiting, the poor don't like high prices, and those in the middle tend to complain about both' (Wildavsky, 1979: 285). Through the cross-national research reported herein, we and our contributors seek to instruct both ourselves and relevant decision agents about the ongoing dilemmas and opportunities that face health policy in the OECD countries today. It is not easy, but we hope that this collective cross-national dialogue will push - or at least nudge - better policies along in a variety of national environments.

\section{Acknowledgement}

We are grateful to an anonymous referee for constructive comments on this editorial and the papers included in this special issue.

\section{References}

Alcock, P., H. Glennerster, A. Oakley and A. Sinfield (eds) (2001), Welfare and Well Being: Richard Titmuss's Contribution to Social Policy, Bristol: Policy Press.

Arrow, K. J. (1963), 'Uncertainty and the welfare economics of medical care', American Economic Review, 53: 941-973.

Audit Commission and Healthcare Commission (2008), Is the Treatment Working? Wetherby: Audit Commission, http://www.audit-commission.gov.uk/nationalstudies/health/ financialmanagement/Pages/isthetreatmentworking.aspx [accessed 13 March 2010].

Bevan, G. (2008), 'Is choice working for patients in the English NHS?', British Medical Journal, 337: a935. 
Bevan, G. (2009), 'The search for a proportionate care law by formula funding in the English NHS', Financial Accountability and Management, 25(1): 391-410.

Bevan, G. and R. Robinson (2005), 'The interplay between economic and political logics: path dependency in health care in England', Journal of Health Politics, Policy and Law, 30(1): 53-78.

Bevan, G. and W. P. M. M. van de Ven (2010), 'Choice of providers and Mutual Healthcare Purchasers: can the English National Health Service learn from the Dutch reforms?', Health Economics, Policy and Law, 5: 343-363.

Brook, R. H., E. B. Keeler, K. N. Lohr, J. P. Newhouse, J. E. Ware, W. H. Rogers, A. R. Davies, D. C. Sherbourne, G. A. Goldberg, P. Camp, C. Kamberg, A. Leibowitz, J. Keesey and D. Reboussin (2006), The Health Insurance Experiment. A Classic RAND Study Speaks to the Current Health Care Reform Debate, RAND: Santa Monica, http://www.rand.org/ pubs/research_briefs/2006/RAND_RB9174.pdf [accessed 13 March 2010].

Coulter, A., N. L. Maistre and L. Henderson (2005), Patients' Experience of Choosing Where to Undergo Surgical Treatment. Evaluation of London Patient Choice Scheme, Oxford: Picker Institute Europe.

Dixon, A., R. Robertson and R. Bal (2010), 'The experience of implementing choice at point of referral: a comparison of the Netherlands and England', Health Economics, Policy and Law, 5: 295-317.

Enthoven, A. C. (1978), 'Consumer-Choice Health Plan; a national-health-insurance proposal based on regulated competition in the private sector', New England Journal of Medicine, 298: 709-720.

Enthoven, A. C. (1980), Health Plan, The Only Practical Solution to the Soaring Cost of Medical Care, Reading, MA: Addison-Wesley.

Enthoven, A. C. (1981), 'The behaviour of health care agents: provider Behaviour', in J. van de Gaag and M. Perlman (eds), Health, Economics and Health Economics, Amsterdam: North Holland, 173-188.

Enthoven, A. (1985), Reflections on the Management of the NHS, London: Nuffield Provincial Hospitals Trust.

Evans, R. G. (1981), 'Incomplete vertical integration: the distinctive structure of the healthcare industry', in J. van de Gaag and M. Perlman (eds), Health, Economics and Health Economics, Amsterdam: North Holland, 329-354.

Evans, R. G. (1987), 'Public health insurance: the collective purchase of individual care', Health Policy, 7: 115-134.

Evans, R. G. (2005), 'Fellow travelers on a contested path: power, purpose, and the evolution of European health care systems', Journal of Health Politics Policy and Law, 30: 277-294.

Evans, R. G., M. L. Barer and C. Hertzman (1991), 'The 20-year experiment: accounting for, explaining and evaluating health care cost containment in Canada and the United States', American Review of Public Health, 12: 481-518.

Evans, R. G., J. Lomas, M. L. Barer, R. J. Labelle, C. Fooks, G. L. Stoddart, G. M. Anderson, D. Feeney, A. Gafni, G. W. Torrance and W. G. Tholl (1989), 'Controlling health expenditures - the Canadian reality', New England Journal of Medicine, 320: 571-577.

Flood, C. M. and A. Haugan (2010), 'Lessons for Canada from regulatory approaches to the public/private divide in Sweden, the UK, the Netherlands, Germany and France', Health Economics, Policy and Law, 5: 319-341.

Fung, C. H., Y.-W. Lim, S. Mattke, C. Damberg and P. G. Shekelle (2008), 'Systematic review: the evidence that publishing patient care performance data improves quality of care', Annals of Internal Medicine, 148: 111-123. 
Greer, S. L. (2008), 'Devolution and divergence in UK health policies', British Medical Journal, 337: a2616.

Ham, C. (1996), 'Contestability: a middle path for health care', British Medical Journal, 312 : $70-71$.

Ham, C. (2000), The Politics of NHS Reform 1988-97, London: King's Fund.

Helderman, J.-K., F. T. Schut, T. E. D. van der Grinten and W. P. M. M. van de Ven (2005), 'Market-oriented health care reforms and policy learning in The Netherlands', Journal of Health Politics Policy and Law, 30: 189-210.

Honigsbaum, F. (1979), The Division in British Medicine: A History of the Separation of General Practice from Hospital Care, 1911-1968, New York: St Martin's Press.

Juran, J. M. (ed.) (1988), Juran's Quality Control Handbook, 4th edn, New York: McGraw-Hill.

Le Grand, J. (2007), The Other Invisible Hand: Delivering Public Services Through Choice and Competition, Princeton, NJ: Princeton University Press.

Light, D. (2000), 'Sociological perspectives on competition in health care', Journal of Health Politics, Policy and Law, 25(5): 969-974.

OECD (2008), OECD Health Data 2008, Paris: OECD.

Or, Z., C. Cases, M. Lisac, K. Vrangbæk, U. Winblad Spångberg and G. Bevan (2010), 'Are health problems systemic? Health reforms under Beveridgian and Bismarkian systems', Health Economics, Policy and Law, 5: 269-293.

Richards, M. (2008), Improving access to medicines for NHS patients, London: Department of Health.

Schlesinger, M. J. (2010), 'Choice cuts: parsing policymakers' pursuit of patient empowerment from an individual perspective', Health Economics, Policy and Law, 5: 365-387.

Schwartz, B. (2004), 'The Tyranny of Choice', Scientific American, 290(4): 70-76.

Secretary of State for Health (2002), Delivering the NHS Plan [CM 5503], London: The Stationery Office, www.dh.gov.uk/PublicationsAndStatistics/Publications/Publications PolicyAndGuidance/PublicationsPolicyAndGuidanceArticle/fs/en?CONTENT_ID=4005818\& chk=zN/Moe [accessed 13 April 2010].

Simon, H. A. (1997), Administrative Behavior a Study of Decision-Making Process in Administrative Organization, 4th edn, New York: Free Press.

Starr, P. (1982), The Social Transformation of American Medicine, New York: Basic Books.

Stevens, R. (2003), Medical Practice in Modern England, New Brunswick: Transaction publishers.

Thaler, R. H. and C. R. Sunstein (2008), Nudge, London: Yale University Press.

Tuohy, C. (1999), Accidental Logics. The dynamics of Change in the Health Care Arena in the United States, Britain and Canada, New York: Oxford University Press.

Tuohy, C. (2008), What Role for Social Insurance in Tax-Financed Healthcare Systems: A Canadian Perspective, London: Presentation to the King's Fund.

van de Ven, W. P. M. M., K. Beck, C. van de Voorde, J. Wasem and I. Zmora (2007), 'Risk adjustment and risk selection in Europe: six years later', Health Policy, 83: 162-179.

van de Ven, W. P. M. M., F. T. Schut, H. E. G. M. Hermans, D. de Jong, M. van der Maat, R. Coppen, P. P. Groenewegen and R. D. Friele (2009), Evaluatie Zorgverzekeringswet en Wet op de zorgtoeslag (Evaluation of the Health Insurance Act and the Health care allowance Act), Den Haag: ZonMw.

Welsh Assembly Government (2008), Proposals to Change the Structure of the NHS in Wales. Consultation Paper, Cardiff: Welsh Assembly Government. 
Weale, A. (1998), 'Rationing health care: a logical solution to an inconsistent triad', British Medical Journal, 316: 410.

Wildavsky, A. (1979), Speaking Truth to Power: The Art and Craft of Policy Analysis, Boston, Mass.: Little Brown.

Wilsford, D. (1989), 'Physicians and the State in France', in G. Freddi and J. W. Björkman (eds), Chapter 6 of Controlling Medical Professionals: The Comparative Politics of Health Governance, London: Sage, 130-156.

Wilsford, D. (1995), 'Path dependency, or why history makes it difficult but not impossible to reform health care systems in a big way', Journal of Public Policy, 14(3): 251-283.

Woods, K. J. (2001), 'The development of integrated health care models in Scotland', International Journal of Integrated Care, 1(1): 1-18. 